\title{
Acute effects of ethanol on left ventricular diastolic function
}

Markku Kupari, Pekka Koskinen, Markku Hynynen, Markku Salmenperä, Markku Ventilä

\section{Departments of Cardiology and Anesthesiology, Helsinki University Central Hospital, Helsinki, Finland M Kupari \\ P Koskinen \\ M Hynynen \\ M Salmenperä \\ $M$ Ventilä \\ Correspondence to Dr Markku Kupari, Cardiovascular Laboratory, Hospital, SF-00290 Helsinki, Finland.}

Accepted for publication 2 April 1990

\begin{abstract}
Transmitral flow velocities were measured by Doppler echocardiography in nine healthy men who ingested $1 \mathrm{~g} / \mathrm{kg}$ of ethanol within one hour. The measurements were made before the first drink and every hour thereafter for three hours. The peak mean (SE) blood ethanol concentration was $21.4(1.0)$ mmol/1. Each man was also studied after drinking fruit juice. Ethanol increased the heart rate but did not change the peak transmitral velocities, the normalised peak filling rate, the deceleration of early flow, or the duration of relaxation as measured from the second heart sound to the peak early diastolic velocity. The ratio of the peak atrial to the peak early diastolic velocity rose from 0.41 $(0.03)$ to $0.44(0.03)$ after ethanol but remained unchanged after juice. The difference between juice and ethanol was independent of changes in heart rate. The fluid balance was more negative in the ethanol experiment $(-727$ (114) $\mathrm{ml} v$ $-107(70) \mathrm{ml}$ ), suggesting a reduction in preload, and the ethanol-induced net loss of fluid correlated with the concomitant change in the velocity ratio.

A moderate dose of ethanol causes a small acute increase of the ratio of the peak atrial to the peak early diastolic velocity of mitral flow in healthy subjects. Although this change indicates altered diastolic function of the left ventricle, most of it may result from the diuretic effect of ethanol. Any major impairment of ventricular relaxation seems unlikely.
\end{abstract}

Even a moderate dose of alcohol can change left ventricular systolic performance through its effects on contractility, heart rate, and loading conditions. ${ }^{1-3}$ Its effects on diastolic function are less certain. In theory, ventricular relaxation could be compromised because alcohol can inhibit calcium cycling in the myocardial cell, at least at high concentrations. ${ }^{45}$ We therefore used Doppler ultrasound to examine the effects of a moderate dose of ethanol on the transmitral blood flow velocities in healthy men. The Doppler method has been shown to be sensitive both to acute and chronic alterations in ventricular diastolic performance. ${ }^{67}$

\section{Subjects and methods}

SUBJECTS AND STUDY DESIGN

The study group consisted of nine male volunteers aged 23 to 28 years. All were healthy-as shown by a clinical examination, a 12 lead electrocardiogram, and cross sectional echocardiography. They used alcohol only in moderation: the reported average consumption ranged from 5 to $35 \mathrm{~g}$ of ethanol/day (median $11 \mathrm{~g} /$ day).

The men entered the cardiovascular laboratory at 3:00 pm having fasted for 6 hours before the study. They emptied their bladders, and an indwelling cannula was inserted into an antecubital vein for blood sampling. Baseline recordings of arterial blood pressure (automated oscillometry), Doppler transmitral flow velocities, and $M$ mode echocardiograms of the left atrium and left ventricle were made after a $\mathbf{3 0}$ minute supine rest. Thereafter the men ingested ethanol $1 \mathrm{~g} / \mathrm{kg}$ as a $15 \%(\mathrm{w} / \mathrm{v})$ dilution in juice within one hour. The measurements described above were repeated every hour up to three hours after they started to drink. The volume of urine excreted during the study was measured and subtracted from the volume of fluid ingested. This gave the net loss of fluid (excluding evaporation and perspiration). Each man also took part in a control experiment in which the ethanol was replaced by the same volume of juice; the order of experiments was randomised. Samples of venous blood were taken to measure the blood ethanol concentration ${ }^{8}$ before ethanol or juice ingestion and $20,40,60,80,100$, 120 , and 180 minutes after the first ethanol drink.

M MODE AND DOPPLER ECHOCARDIOGRAPHY We used a Toshiba SSH-60A echocardiograph equipped with a $3.7 \mathrm{MHz}$ phased array transducer and a strip chart recorder for the cross sectional and $M$ mode echocardiographic studies. The $M$ mode recordings of the left ventricle and left atrium were taken through the sector scan by methods described in detail elsewhere. ${ }^{9}$

The pulsed Doppler recordings of the transmitral flow were made with a Toshiba SDS-60A Doppler unit (incorporated into the SSH-60A scanner) and a $2.5 \mathrm{MHz}$ transducer. This system analyses the Doppler shifts by a fast Fourier transform and displays the velocity spectra every $5 \mathrm{~ms}$ in real time. All studies were made with the man lying in the left lateral position and from an apical transducer position. With cross sectional guidance 
we placed the sample volume between the mitral valve leaflets just distal to the mitral annulus, with the ultrasound beam directed in parallel with the assumed left ventricular inflow. The position and size of the sample volume were thereafter adjusted according to the Doppler signal to obtain maximal and clearly defined velocity waveforms. No angle correction was applied. The velocity spectra were recorded during quiet respiration together with an electrocardiogram and an external phonocardiogram at a paper speed of $50 \mathrm{~m} / \mathrm{s}$.

$M$ mode and Doppler recordings were coded and analysed blindly with a tablet digitiser and computer assistance. The left ventricular end diastolic diameter and the left atrial diameter were measured according to the European standardisation. ${ }^{10}$ The midpoints of the darkest portions of the Doppler velocity waveforms were traced on the digitising tablet and the computer automatically calculated the peak late (atrial) and early diastolic velocities, their arithmetic ratio, and the ratio of the peak early diastolic velocity to the total time velocity integral-that is the normalised peak filling rate according to Bowman et al. ${ }^{11}$ The relaxation time was measured from the beginning of the second heart sound on the phonocardiogram to the point of the peak early diastolic velocity; this time covers the period of relaxation more completely rather than merely the duration of isometric relaxation. ${ }^{12}$ We determined the deceleration of the early flow by fitting a straight line to the first half of the down slope of the early velocity wave. All measurements were the average of five cardiac cycles.

\section{REPRODUCIBILITY}

In five healthy men aged 32 to 42 years we recorded transmitral flow velocities twice under identical conditions at an interval of one hour. As in our ethanol study, the first recording was preceded by a 30 minute rest and the men lay supine between the recordings. The reproducibility of the Doppler measurements was assessed by the method of Bland and Altman ${ }^{13}$ by taking square roots of the mean square differences between the two examinations. These (that is, the standard deviations of the differences) were as follows: $4.5 \mathrm{~cm} / \mathrm{s}$
- for the peak early velocity, $3.8 \mathrm{~cm} / \mathrm{s}$ for the peak late velocity, 0.05 for the late to early peak velocity ratio, $64 \mathrm{~cm} / \mathrm{s}^{2}$ for the deceleration of flow, $10 \mathrm{~ms}$ for the relaxation time, and $0.4 / \mathrm{s}$ for the normalised peak filling rate. These figures compare well with the reproducibility data reported recently by Fast et al and Spirito et al. ${ }^{14}{ }^{15}$ The reproducibility of our $M$ mode echocardiographic technique has been reported earlier. ${ }^{9}$

\section{STATISTICAL ANALYSIS}

We used methods available in the BMDP statistical software. Because the men served as their own controls, repeated measurements analysis of variance and covariance with no grouping factor and time and treatment as within factors were used to compare the effects of ethanol and juice on the cardiovascular measurements (BMDP 2V). ${ }^{16}$ Heart rate was used as a covariate that changed over al levels of the within factors to adjust for the rate dependency of the Doppler velocity measurements. ${ }^{17}$ In analysing changes in the late to early peak velocity ratio we used the net loss of fluid during the experiment as a second covariate (changing over the levels of treatment) to adjust for the preload sensitivity of this measurement. ${ }^{17} \mathrm{We}$ used the least squares method for correlation analysis. We used a paired $t$ test to compare the fluid balance between the ethanol and juice experiments. All tests were two tailed; $p$ values $<0.05$ were regarded as statistically significant. The data are given as mean (SE).

\section{Results}

BLOOD ETHANOL

The blood ethanol concentration was $<0.6$ $\mathrm{mmol} / \mathrm{l}$ in each man before both ethanol and juice ingestion. After ethanol intake blood ethanol measured $16.5(0.8) \mathrm{mmol} / \mathrm{l}$ at the completion of the drinking period, $21.0(1.0)$ $\mathrm{mmol} / 140 \mathrm{minutes}$ later, and $18.3(1.0) \mathrm{mmol} / \mathrm{l}$ at the end of the experiment. The fluid balance was $-727(114) \mathrm{ml}$ after ethanol and $-107(70)$ $\mathrm{ml}$ after juice $(\mathrm{p}<0.001)$.

\section{CARDIOVASCULAR MEASUREMENTS}

Table 1 summarises the data on heart rate

Table 1 Heart rate, blood pressure, left ventricular end diastolic diameter, and left atrial diameter (mean (SEM)) before and after ingestion of ethanol (1 g/kg within one hour) or an equal volume of juice

\begin{tabular}{|c|c|c|c|c|c|c|c|c|c|c|c|c|c|}
\hline \multirow[b]{3}{*}{ Measurement } & & \multirow{2}{*}{\multicolumn{8}{|c|}{ Time (h) after drinking started }} & & $F$ values ${ }^{\star}$ & \multirow[b]{3}{*}{ Time } & \multirow{3}{*}{$\begin{array}{l}\text { Treatment } \\
\times \text { time } \\
\text { interaction }\end{array}$} \\
\hline & & & & & & & & & & & \multirow[b]{2}{*}{ Treatment } & & \\
\hline & & \multicolumn{2}{|l|}{0} & \multicolumn{2}{|l|}{1} & \multicolumn{2}{|l|}{2} & \multicolumn{2}{|l|}{3} & & & & \\
\hline Heart rate (beats/min) & \multirow{7}{*}{$\begin{array}{l}\mathbf{J} \\
\mathbf{E} \\
\mathbf{J} \\
\mathbf{E} \\
\mathbf{J} \\
\mathbf{E} \\
\mathrm{J} \\
\mathrm{E} \\
\mathbf{J} \\
\mathrm{E}\end{array}$} & \multirow{7}{*}{\multicolumn{2}{|c|}{$\begin{aligned} 55 & (2) \\
52 & (2) \\
106 & (4) \\
107 & (3) \\
63 & (2) \\
62 & (3) \\
51 \cdot 7 & (0 \cdot 8) \\
52 \cdot 0 & (0 \cdot 6) \\
34 \cdot 8 & (1.5) \\
34 \cdot 6 & (1.3)\end{aligned}$}} & \multirow{7}{*}{\multicolumn{2}{|c|}{$\begin{aligned} 52 & (2) \\
56 & (2) \\
109 & (3) \\
111 & (3) \\
64 & (1) \\
62 & (3) \\
51.6 & (0 \cdot 7) \\
51.8 & (0.7) \\
35.3 & (1.4) \\
35 \cdot 1 & (1.4)\end{aligned}$}} & \multirow{7}{*}{\multicolumn{2}{|c|}{$\begin{array}{cl}54 & (2) \\
56 & (3) \\
110 & (2) \\
108 & (3) \\
65 & (2) \\
60 & (3) \\
51 \cdot 5 & (0 \cdot 5) \\
50.7 & (0.7) \\
33.6 & (1.4) \\
33.8 & (1.0)\end{array}$}} & \multirow{7}{*}{$\begin{array}{c}51 \\
56 \\
111 \\
108 \\
67 \\
63 \\
51 \cdot 1 \\
50 \cdot 5 \\
32 \cdot 8 \\
31 \cdot 8\end{array}$} & \multirow{7}{*}{$\begin{array}{l}(2) \\
(2) \\
(3) \\
(3) \\
(2) \\
(2) \\
(0 \cdot 7) \\
(0 \cdot 7) \\
(1 \cdot 4) \\
(1 \cdot 1)\end{array}$} & & $8.8 \dagger$ & 0.5 & $7 \cdot 9 \ddagger$ \\
\hline Systolic blood pressure (mm Hg) & & & & & & & & & & & 0.2 & 1.4 & 0.8 \\
\hline & & & & & & & & & & , & & & \\
\hline Diastolic blood pressure (mm $\mathrm{Hg})$ & & & & & & & & & & $r^{\prime}$ & $4 \cdot 3$ & $1 \cdot 3$ & 0.5 \\
\hline LV end diastolic diameter (mm) & & & & & & & & & & & 0.2 & $3 \cdot 7 \dagger$ & 1.0 \\
\hline Left atrial diameter $(\mathrm{mm})$ & & & & & & & & & & & 0.1 & $17 \cdot 5 \S$ & 0.5 \\
\hline & & & & & & & & & & & & & \\
\hline
\end{tabular}

*F values from repeated measurements analysis of variance; the degrees of freedom are 1,8 for the treatment effect and 3 , 24 for the effects of time and the treatment $x$ time interaction. tp $<0.05 ; \ddagger \mathrm{p}<0.01 ; \S \mathrm{p}<0.001$. E, ethanol; J, juice; LV, left ventricular. 
Table 2 Doppler velocimetry of mitral flow before and after ingestion of ethanol (1 $\mathrm{g} / \mathrm{kg}$ within one hour) or an equal volume of juice (mean (SEM))

\begin{tabular}{|c|c|c|c|c|c|c|c|c|c|c|c|c|c|}
\hline \multirow[b]{3}{*}{ Measurement } & & & & & & & & & & \multicolumn{4}{|l|}{$F$ values ${ }^{\star}$} \\
\hline & & \multicolumn{8}{|c|}{ Time (h) after drinking started } & \multirow[b]{2}{*}{ Treatment } & \multirow[b]{2}{*}{ Time } & \multirow{2}{*}{$\begin{array}{l}\text { Treatment } \\
\times \text { time } \\
\text { interaction }\end{array}$} & \multirow{2}{*}{$\begin{array}{l}\text { Heart } \\
\text { rate }\end{array}$} \\
\hline & & 0 & & 1 & & 2 & & 3 & & & & & \\
\hline Peak atrial velocity $(\mathrm{cm} / \mathrm{s})$ & $\mathrm{J}_{\mathrm{E}}$ & $\begin{array}{l}24 \\
24\end{array}$ & (2) & 23 & (2) & $\begin{array}{l}22 \\
25\end{array}$ & (1) & $\begin{array}{l}22 \\
24\end{array}$ & (2) & $4 \cdot 9$ & 1.9 & 0.4 & $9 \cdot 4 \dagger$ \\
\hline $\begin{array}{l}\text { Peak early diastolic velocity } \\
(\mathrm{cm} / \mathrm{s})\end{array}$ & $\mathrm{J}_{\mathbf{E}}^{\mathrm{L}}$ & $\begin{array}{l}24 \\
61 \\
61\end{array}$ & $\begin{array}{l}(3) \\
(4)\end{array}$ & $\begin{array}{l}20 \\
60 \\
62\end{array}$ & $\begin{array}{l}(4) \\
(4)\end{array}$ & $\begin{array}{l}23 \\
58 \\
59\end{array}$ & $\begin{array}{l}(4) \\
(4)\end{array}$ & $\begin{array}{l}27 \\
57 \\
59\end{array}$ & (3) & $0 \cdot 1$ & $4.0 \dagger$ & $2 \cdot 9$ & 0.0 \\
\hline $\begin{array}{l}\text { Atrial to early peak velocity } \\
\text { ratio }\end{array}$ & $\overline{\mathrm{J}}$ & $\begin{array}{l}0 \cdot 39 \\
0.41\end{array}$ & $\begin{array}{l}(0.03) \\
(0.03)\end{array}$ & $\begin{array}{l}0.40 \\
0.44\end{array}$ & $\begin{array}{l}(0.03) \\
(0.04)\end{array}$ & $\begin{array}{l}0.39 \\
0.44\end{array}$ & $\begin{array}{l}(0.03) \\
(0.03)\end{array}$ & $\begin{array}{l}0.39 \\
0.43\end{array}$ & $\begin{array}{l}(0.04) \\
(0.04)\end{array}$ & $10 \cdot 6 \dagger$ & $0 \cdot 2$ & $1 \cdot 1$ & 6.9 \\
\hline $\begin{array}{l}\text { Deceleration of early flow } \\
\left(\mathrm{cm} / \mathrm{s}^{2}\right)\end{array}$ & $\underset{\mathbf{E}}{\mathbf{J}}$ & $\begin{array}{l}420 \\
426\end{array}$ & $\begin{array}{l}(33) \\
(40)\end{array}$ & $\begin{array}{l}428 \\
450\end{array}$ & $\begin{array}{l}(57) \\
(40)\end{array}$ & $\begin{array}{l}370 \\
414\end{array}$ & $\begin{array}{l}(28) \\
(42)\end{array}$ & $\begin{array}{l}375 \\
418\end{array}$ & $\begin{array}{l}(27) \\
(40)\end{array}$ & 0.0 & $2 \cdot 0$ & $0 \cdot 7$ & $0 \cdot 3$ \\
\hline Peak normalised filling rate $\left(\mathrm{s}^{-1}\right)$ & $\mathrm{J}_{\mathbf{E}}^{\mathbf{J}}$ & $\begin{array}{l}4 \cdot 1 \\
4 \cdot 2\end{array}$ & $\begin{array}{l}(0 \cdot 1) \\
(0 \cdot 1)\end{array}$ & $\begin{array}{l}4 \cdot 1 \\
4 \cdot 5\end{array}$ & $\begin{array}{l}(0 \cdot 1) \\
(0 \cdot 2)\end{array}$ & $\begin{array}{l}4 \cdot 2 \\
4 \cdot 2\end{array}$ & $\begin{array}{l}(0 \cdot 1) \\
(0 \cdot 1)\end{array}$ & $\begin{array}{l}4 \cdot 1 \\
4 \cdot 4\end{array}$ & $\begin{array}{l}(0 \cdot 2) \\
(0 \cdot 1)\end{array}$ & 0.4 & 1.7 & 0.7 & $7 \cdot 8 \dagger$ \\
\hline Relaxation time (ms) & $\overrightarrow{\mathbf{J}}$ & $\begin{array}{l}196 \\
207\end{array}$ & $\begin{array}{l}(8) \\
(9)\end{array}$ & $\begin{array}{l}190 \\
196\end{array}$ & $\begin{array}{l}(6) \\
(6)\end{array}$ & $\begin{array}{l}193 \\
196\end{array}$ & $\begin{array}{l}(6) \\
(6)\end{array}$ & $\begin{array}{l}194 \\
196\end{array}$ & $\begin{array}{l}(6) \\
(4)\end{array}$ & $0 \cdot 0$ & $1 \cdot 6$ & $1 \cdot 3$ & $6 \cdot 8 \dagger$ \\
\hline
\end{tabular}

$\star F$ values from repeated measurements analysis of covariance with heart rate as a changing covariate; the degrees of freedom are 1,7 for the effects of treatment and heart rate and 3, 23 for the effect of time and for the treatment $x$ time interaction. $\quad t p<0.05$. E, ethanol; $\mathrm{J}$, juice.

blood pressure, and left ventricular and atrial diameters. The results of the analyses of variance are also given. Compared with juice, ethanol increased heart rate $(p=0.018$ for the treatment effect and $p=0.001$ for the treatment $\times$ time interaction) but did not give a statistically significant change in either systolic or diastolic blood pressure or the diameters of the left ventricle or the left atrium.

Table 2 summarises the Doppler velocity measurements and the results of the repeated measurements analyses of covariance. A statistically significant treatment effect (that is, an effect of ethanol independent of the effects of time and heart rate) was found only in the ratio of late to early peak velocity, which rose from $0.41(0.03)$ to $0.44(0.03) 2$ hours after ethanol but was unchanged 2 hours after juice $(p=$ 0.014 ) (figure). There was a modest direct correlation $(r=0.50)$ between the net loss of fluid and the change in the peak velocity ratio from the baseline to the 3 hour recording in the ethanol study, suggesting that the larger the diuresis the more prominent was the rise in the peak velocity ratio. When the net loss of fluid was included as a second covariate in the analysis the treatment effect on the velocity ratio became non-significant $(F=1 \cdot 22, p=$ 0.312 ).

\section{Discussion}

The study of left ventricular diastolic function by Doppler echocardiography is based on
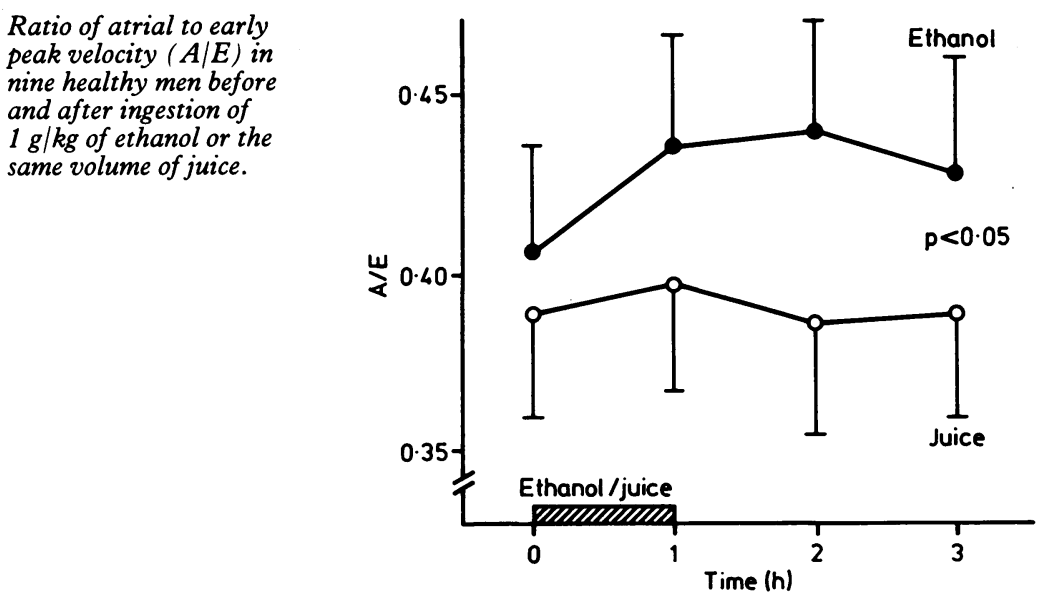

measuring the velocity of blood flow through the mitral valve during ventricular filling. This technique has rapidly gained in popularity because it is non-invasive, simple, and repeatable. Velocity derived indices of ventricular filling correlate with both cineangiographic ${ }^{18}$ and radionuclide angiographic ${ }^{11}$ data, and simultaneous catheterisation and Doppler studies have shown that the method can expose both relaxation and compliance abnormalities of the left ventricle. ${ }^{19}$ A limitation of this technique is that in addition to diseases and therapeutic interventions factors such as age, heart rate, loading conditions, and left atrial pressure can also influence the transmitral velocities. ${ }^{717}$ In our study, both heart rate and time seemed to have significant effects (see table 2). Although the effect of time, a novel finding, may simply be a reflection of the present experimental conditions, it could as well indicate diurnal variation in diastolic function and therefore deserves further study.

Analysis and interpretation of the Doppler data for differences or changes in the intrinsic ventricular diastolic properties must take into account the contribution of the confounding factors such as time and heart rate. When groups of patients are studied this can be done in part by proper use of statistical techniques. We have found methods of covariance analysis very useful in this respect, both in cross sectional between-group comparisons and, as the present work shows, in studying serial changes in diastolic function. These techniques do not solve the problem of interpreting individual data, however, which probably need nomograms adjusted for age and heart rate at least.

\section{ETHANOL AND DIASTOLIC FUNCTION}

We found that ethanol induced a small increase in the ratio of late to early peak velocity. An increase in heart rate, ${ }^{20}$ a reduction in preload, ${ }^{21}$ or an impairment of relaxation ${ }^{19}$ could produce this. We think that a reduction in preload was the most likely mechanism in our study because the change was rate independent, there were no differences in the relaxation time or in the deceleration of flow, and the change in the velocity ratio correlated with the amount of fluid loss that ethanol provoked. This interpretation accords with the results of covariance analysis in which the treatment effect was 
adjusted for the fluid loss, and it also accords with previous reports showing that ethanol reduced preload in healthy people ${ }^{1222}$ and in patients with congestive heart failure. ${ }^{23}$ As in our earlier study, ${ }^{2}$ we found bigger reductions in the sizes of the left ventricle and atrium after ethanol than after juice, indicating that ethanol affected the preload (but not significantly). A reduction in preload changes the velocity ratio by decreasing the peak early velocity or, in addition, by increasing peak late velocity. ${ }^{21}{ }^{24} \mathrm{In}$ our study the rise in the velocity ratio was apparently mainly the result of a change in the atrial component, though again the effect of ethanol on the peak atrial velocity did not quite reach statistical significance $(\mathrm{F}=4.9, \mathrm{p}=$ 0.06 ; see table 2).

Both experimental and clinical studies suggest that prolonged and heavy use of alcohol can impair left ventricular filling before or concomitantly with contractile deterioration. In a canine model of chronic alcoholism, the first myocardial abnormality to appear was a decrease in left ventricular compliance, ${ }^{25}$ and in alcoholic patients left ventricular end diastolic pressure may be increased despite a normal or even a decreased end diastolic volume. ${ }^{26}$ Recently, Silberbauer et al reported the results of Doppler velocimetry in alcoholic patients who were free of clinically evident heart disease. ${ }^{27}$ Compared with healthy controls, alcoholic patients showed changes in the peak velocity ratio and in the isovolumetric relaxation time indicative of impaired relaxation despite normal left ventricular mass and systolic performance. Although chronic heavy drinking seems to impair left ventricular diastolic function, our data suggest that a single modest dose of alcohol does not produce comparable adverse effects in healthy men.

We thank the Finnish Foundation for Alcohol Research for financial support.

1 Lang RM, Borow KM, Neumann A, Feldman T. Adverse cardiac effects of acute alcohol ingestion in young adults. Ann Intern Med 1985;102:742-7.

2 Kupari M. Acute cardiovascular effects of ethanol: a controlled non-invasive study. Br Heart J 1983;49:174-82.

3 Kelbaek H, Gjorup T, Brynjolf I, Christensen NJ Godtfredsen J. Acute effects of alcohol on left ventricular Godtfredsen J. Acute effects of alcohol on left ventricular function in healthy subjects at rest and

4 Gvozdjak A, Kruty F, Bada V, Niederland TE, Gvozdjak J. The effects of ethanol on myocardial mitochondrial and sarcoplasmic ATPase in rats. Cor Vasa 1977;19:237-42.

5 Swartz M, Repke DI, Katz AM, Rubin E. Effects of ethanol on calcium binding and uptake by cardiac microsomes. Biochem Pharmacol 1974;23:2369-76.
6 Wind BE, Snider AR, Buda AJ, O’Neill WW, Topol EJ, Dilworth LR. Pulsed Doppler assessment of left ventricular diastolic filling in coronary artery disease before and immediately after coronary angioplasty. $\mathrm{Am} \mathrm{J} \mathrm{Cardiol}$ 1987;59:1041-6.

7 Spirito P, Maron BJ. Doppler echocardiography for assessing left ventricular diastolic function. Ann Intern Med 1988;109:122-6.

8 Eriksson CJP, Sippel HW, Forsander OA. The determination of acetaldehyde in biological samples by head-space gas chromatography. Anal Biochem 1977;80:116-24.

9 Kupari M. Reproducibility of M-mode echocardiographic assessment of left ventricular function. Significance of the temporal range of measurements. Eur Heart $J$ 1984;5: 412-8.

10 Roelandt J, Gibson DG. Recommendations for the standardization of measurements for M-mode echocardiograms. Eur Heart J 1980;1:375-8.

11 Bowman LK, Lee FA, Jaffe CC, Mattera J, Wackers FJT, Zaret BL. Peak filling rate normalized to mitral stroke volume: a new Doppler echocardiographic filling index validated by radionuclide angiographic techniques. $J A m$ Coll Cardiol 1988;12:937-43.

12 Nishimura RA, Housmans PR, Hatle LK, Tajik AJ.Assessment of diastolic function of the heart: background and current applications of Doppler echocardiography. Part I. Physiologic and pathophysiologic features. Mayo Clin Proc 1989;64:71-81.

13 Bland JM, Altman DG. Statistical methods for assessing agreement between two methods of clinical measurement. Lancet 1986;i:307-10.

14 Fast J, van Dam I, Heringa A, et al. Limits of reproducibility of mitral pulsed Doppler spectra. Am J Cardiol 1988;61: $891-4$.

15 Spirito P, Maron BJ, Verter I, Merrill JS. Reproducibility of Doppler echocardiographic measurements of left ventricular diastolic function. Eur Heart J 1988;9:879-86.

16 Jennrich R, Sampson P, Frane J. Analysis of variance and covariance including repeated measures. In: Dixon WS, Brown MB, Engelman L, et al. BMDP statistical software. Berkeley, California: University of California Press, 1985 359-87.

17 Nishimura RA, Housmans PR, Hatle LK, Tajik AJ. Assessment of diastolic function of the heart: background and current applications of Doppler echocardiography. Pa II. Clinical studies. Mayo Clin Proc 1989;64:181-204.

18 Ferguson JJ, Manning WJ, Come PC. Pulsed Dopple echocardiographic determination of the time course of left ventricular filling: validation with cineangiography. $\mathrm{Am}$ Heart J 1989;117:127-32.

19 Appleton CP, Hatle LK, Popp RL. Relation of transmitral flow velocity patterns to left ventricular diastolic function: new insights from a combined hemodynamic and Doppler echocardiographic study. J Am Coll Cardiol 1988;12: 426-40.

20 Smith SA, Stoner JE, Russell AE, Sheppard JM, Aylward PE. Transmitral velocities measured by pulsed Doppler in healthy volunteers: effects of acute changes in blood pressure and heart rate. Br Heart J 1989;61:344-7.

21 Choong CY, Herrman HC, Weyman AE, Fifer MA. Preload dependence of Doppler-derived indexes of left ventricular diastolic function in humans. J Am Coll Cardiol 1987;10: 800-8.

22 Koskinen P, Kupari M, Nieminen MS, et al. Effects of alcohol on systemic and pulmonary hemodynamics in normal humans. Clin Cardiol 1986;9:479-82.

23 Greenberg BH, Shutz R, Grunkemeier GL, Griswold H. Acute effects of alcohol in patients with congestive heart failure. Ann Intern Med 1982;97:171-5.

24 Bhatia SJS, Theard MA, Plappert T, St John Sutton MG. Effects of altered loading conditions on transmitral Doppler blood flow velocity [Abstract]. Circulation 1987;76 (suppl IV):124.

25 Thomas G, Haider B, Oldewurtel HA, Lyons MM, Yeh CK, Regan TJ. Progression of myocardial abnormalities in experimental alcoholism. Am J Cardiol 1980;46:233-41.

26 Ahmed SS, Levinson GE, Fiore JJ, Regan TJ. Spectrum of heart muscle abnormalities related to alcoholism. Clin Cardiol 1980;3:335-41.

27 Silberbauer $K$, Juhasz $M$, Ohrenberger G, Hess C. Noninvasive assessment of left ventricular diastolic function by pulsed Doppler echocardiography in young alcoholics. Cardiology 1988;75:431-9. 